\title{
Efficacy of transfusion pre-medications on attenuating transfusion reaction in adults: A systematic review and meta-analysis
}

\section{Shiyuan Yu}

Peking Union Medical College Hospital

Yawei Liu

Guard bureau of joint staff department

\section{Yanxia Gao}

Peking Union Medical College Hospital

Xin Lu

Peking Union Medical College Hospital

\section{Lina Zhao}

Peking Union Medical College Hospital

\section{Zengzheng Ge}

Peking Union Medical College Hospital

Huadong Zhu

Peking Union Medical College Hospital

Li Yi ( $\nabla$ billliyi@126.com )

Peking Union Medical College Hospital

\section{Research}

Keywords: Transfusion pre-medications, transfusion reaction, meta-analysis

Posted Date: April 28th, 2020

DOI: https://doi.org/10.21203/rs.3.rs-24651/v1

License: @ (i) This work is licensed under a Creative Commons Attribution 4.0 International License. Read Full License 


\section{Abstract}

Background - Transfusion pre-medications are generally administered in patients prior to blood transfusion. However, the use of transfusion pre-medications is largely experience-based instead of evidence-based. Our meta-analysis aimed to combine the most updated evidence and demonstrate the efficacy of transfusion pre-medications on attenuating transfusion reaction among patients.

Material and Method - Pubmed, EMBASE, Cochrane Library, Wanfang database, CNKI, CMB was searched for related articles. Data from transfusion pre-medications treated group and transfusion pre-medications free group was collected. Baseline characteristics between groups were compared using SPSS 19.0. RevMan 5.3 was used to pool the collected data for meta-analysis between groups. OR and SMD were used to demonstrate the outcomes.

Results - Eight eligible articles ( 6 case control studies and 2 RCT) were identified, including 22060 cases. Administered transfusion pre-medications included dexamethasone, chlorpheniramine or promethazine. Baseline characteristics showed no significant difference between groups regarding age and gender. There was no significant difference between transfusion pre-medications treated group and transfusion pre-medications free group concerning the rate of fever, itchy, rash, airway spasm and overall transfusion reaction.

Conclusion - Dexamethasone, chlorpheniramine or promethazine is probably not a candidate for prevention of transfusion reaction. Avoiding experienced use of such transfusion pre-medications before blood transfusion may reduce the number of adverse drug reaction and clinical trial is still needed in the future to figure out the treatment for alleviating transfusion reaction.

\section{Introduction}

Blood transfusion is a traditional therapy for hemorrhagic shock, severe blood cell loss and destruction, and other cause of anemia ${ }^{[1]}$. Blood transfusion helps to promote oxygen transport and improve micro circulatory conditions ${ }^{[2]}$. In those patients suffering from complex trauma, blood transfusion is a required replacement therapy during the pre-and intra-operative surgical hemostasis.

The estimated rate of overall transfusion reaction is $2-5 \%$, while the two main major causes of transfusion reaction is febrile non-hemolytic transfusion reaction and allergic reactions ${ }^{[3]}$. Other causes of transfusion reaction include acute or delayed hemolytic reaction, post-transfusion purpura, circulatory overload and so on ${ }^{[3,4]}$. The severity of those reactions varies and cannot be predicted before transfusion ${ }^{[5-7]}$. Although blood type and potential antibodies in the blood is tested before transfusion, transfusion reaction still occurs. Transfusion reaction is now thought to be related to immunological system activation and inflammatory factors release such as IL-1, TNF-a ${ }^{[8-10]}$. However, the mechanism of these inflammatory reactions after blood transfusion is not completely clarified ${ }^{[11,12]}$. Mild transfusion reaction includes fever, itchy, rash, while severe transfusion reaction can lead to death such as airway spasm and allergic shock.

Transfusion pre-medications, such as dexamethasone, chlorpheniramine or promethazine, are administered before transfusion to prevent allergic reaction during and after blood transfusion in some medical centers ${ }^{[13]}$. For example, administering dexamethasone $2 \mathrm{mg}$ through IV line before transfusion is a routine procedure in our hospital, which is one of the largest medical centers in China. Although the dose of these kinds of drugs administered before transfusion is small, it is enough to cause adverse drug effect such as the disseminated of infection, stressed ulcer, and even gastrointestinal hemorrhage. A randomized controlled trial conducted in thalassemia adolescent indicated that oral acetaminophen and intravenous Chlorpheniramine may not decrease the rate of transfusion reaction ${ }^{[14]}$. Nevertheless, 
there is only a few studies focusing on the outcomes of transfusion after the treatment of transfusion pre-medications in adults, and current evidence is rather lacking.

Our meta-analysis aimed to synthesis the most updated researches concerning the outcomes of administering dexamethasone, chlorpheniramine or promethazine before blood transfusion, in order to provide high quality evidence for the use of transfusion pre-medications before transfusion. Our hypothesis is that administering dexamethasone, chlorpheniramine or promethazine before transfusion is able to reduce the rate of allergic reaction.

\section{Methods}

\section{Search strategy}

Pubmed, EMBASE, Cochrane library, Chinese National Knowledge Infrastructure (CNKI), Chinese Biomedical literature(CBM) and Wanfang are screened by two reviewers independently for studies published. English search term included transfusion, blood transfusion, reaction, adverse effect, side effect, dexamethasone, glucocorticoid, steroid, chlorpheniramine and promethazine. Chinese search term included words meaning blood transfusion, dexamethasone, chlorpheniramine, promethazine and adverse effect, including 'shu xue fafan ying', 'yibingqin', 'puermin', 'Ivbennamin' and 'di sai mi song'. All reference lists from the main reports were cross checked independently by two members of our team.

\section{Inclusion and exclusion criteria}

Articles were included if meeting all the following criteria.

1) Researches focusing on transfusion reaction

2) Studies published in English or Chinese

3) Studies including comparison between transfusion pre-medications treated and transfusion pre-medications free patients before blood transfusion

4) One or more of the following outcomes was reported in the articles, rate of fever, rate of itchy skin, rate of rash, rate of airway spasm and overall transfusion reaction rate.

Articles were excluded if any of the following presents.

1) Studies not carried out on human beings

2) Data is not able to extract

3) Articles mainly on population with auto immune disease or immunodeficiency disease.

4) Main aim of using transfusion pre-medications is not preventive

5) Reviews and case reports

\section{Quality assessment}

Two reviewers independently reviewed the included studies using Cochrane Collaboration's tool. The following seven items were evaluated, random sequence generation, allocation concealment, blinding of participants and personnel, 
blinding of outcome assessment, incomplete outcome data, selective reporting and other sources of bias. The results were classified as low risk of bias, high risk of bias and unclear risk of bias.

\section{Statistics analysis}

The baseline characteristics and available data of each article were evaluated and extracted separately by two researchers using Microsoft Excel 2016. The main outcomes are rate of febrile non hemolytic, rate of itchy skin, rate of rash, rate of airway spasm and overall transfusion reaction rate. We use odds ratio (OR) for binary variables and standardized mean difference (SMD) for continuous variables. The estimated OR , 95\% convinced interval $(95 \% \mathrm{Cl})$ and SMD are pooled by Review Manager 5.3. Then the statistics was divided into subgroups according to different kinds of transfusion pre-medications. $P$ value less than 0.05 is defined as significant difference. $I^{2}$ is used to estimate the heterogeneity level of included studies. $I^{2}>50 \%$ is defined as high heterogeneity among studies and a randomized model is conducted to pool the data, while a fixed model was conducted if $\mathrm{I}^{2}$ is no more than $50 \%$. Reporting bias is evaluated by funnel plot.

\section{Results}

\section{Included studies}

Our meta-analysis identified 836 potentially eligible articles, including 459 articles from Pubmed, 324 articles from EMBASE, 0 articles from Cochrane library, 21 from CNKI, 17 from CBM and 15 from Wanfang. All eight articles from CNKI database were eventually identified after abstract and full-text screening, recruiting 23131 transfusion cases in total ${ }^{[15-22]}$. The screening process is shown in Fig. 1. All of identified articles were published in Chinese, including 6 case control studies and 2 RCT. Details of the included articles are shown in Table1.

\section{Baseline characteristics of included articles}

Four eligible studies recruited 23131 patients undergoing blood transfusion in total. There are 9222 transfusion cases in transfusion pre-medications treated group and 13909 transfusion cases in transfusion pre-medications free group. Main characteristics of the patients are shown in Table2. Baseline characteristics show no significant difference between patients divided into transfusion pre-medications treated or transfusion pre-medications free group.

\section{Risk of bias}

The methodological quality of selected trials was assessed using the Cochrane Collaboration's tool. Two of the identified studies was RCT and reported the method of random sequences generation, but one of them failed to report details about allocation concealment, while both failed to report blinding of patient and outcome assessment. There is not incomplete outcome date and selective report regarding the included RCT while the risk of other bias is unclear in one of the RCTs. Among the other 6 case control studies, there was no incomplete outcome date and selective report, but only one of them suggested low risk of other bias. Therefore, all 8 included studies were judged to be of a poor methodological quality. Risk of bias was shown in Fig. 2 and 3.

\section{Outcomes of overall transfusion pre-medications on transfusion reaction}

- Rate of febrile non hemolytic

Seven studies include eligible data on rate of febrile non hemolytic between transfusion pre-medications treated and transfusion pre-medications free patients before blood transfusion, consisting of 18386 cases. A fixed model was conducted because of low heterogeneity among studies (I2=0\%). Pooled statistics showed no significant difference 
between transfusion pre-medications treated and transfusion pre-medications free group concerning rate of fever caused by blood transfusion. [OR=0.70, 95\% Cl $(0.46,1.06), p=0.10]$.

\section{- Rate of itchy skin}

Two studies include eligible data on rate of itchy skin between transfusion pre-medications treated and transfusion premedications free patients before blood transfusion, consisting of 4955 cases. A fixed model was conducted because of low heterogeneity among studies $(12=0 \%)$. Pooled statistics showed no significant difference between transfusion premedications treated and transfusion pre-medications free group concerning rate of itchy skin caused by blood transfusion. [OR=0.73, 95\% $\mathrm{Cl}(0.31,1.68), \mathrm{p}=0.45]$.

- Rate of rash

Two studies include eligible data on rate of rash between transfusion pre-medications treated and transfusion premedications free patients before blood transfusion, consisting of 5247 cases. A fixed model was conducted because of low heterogeneity among studies $(12=0 \%)$. Pooled statistics showed no significant difference between transfusion premedications treated and transfusion pre-medications free group concerning rate of rash caused by blood transfusion. [OR=1.19, 95\% Cl $(0.55,2.58), \mathrm{p}=0.67]$.

\section{- Rate of overall transfusion reaction}

All Seven included studies include eligible data on overall rate of transfusion reaction between transfusion premedications treated and transfusion pre-medications free patients before blood transfusion, consisting of 22839 cases. A fixed model was conducted because of low heterogeneity among studies (I2=0\%). Pooled statistics showed no significant difference between transfusion pre-medications treated and transfusion pre-medications free group concerning overall rate of transfusion reaction caused by blood transfusion. [OR=0.82, 95\% $\mathrm{Cl}(0.62,1.09), p=0.16]$. Outcomes of transfusion pre-medications on preventing transfusion reaction are illustrated in Fig. 4.

\section{Outcomes of dexamethasone on transfusion reaction}

\section{- Rate of febrile non hemolytic}

Three studies include eligible data on rate of febrile non hemolytic between dexamethasone treated and dexamethasone free patients before blood transfusion, consisting of 14177 cases. A fixed model was conducted because of low heterogeneity among studies $(I 2=0 \%)$. Pooled statistics showed no significant difference between dexamethasone treated and dexamethasone free group concerning rate of fever caused by blood transfusion. [OR=0.67, 95\% Cl $(0.29,1.51), p=0.33]$.

- Rate of itchy skin

Two studies include eligible data on rate of itchy skin between dexamethasone treated and dexamethasone free patients before blood transfusion, consisting of 4955 cases. A fixed model was conducted because of low heterogeneity among studies (I2=0\%). Pooled statistics showed no significant difference between dexamethasone treated and dexamethasone free group concerning rate of itchy skin caused by blood transfusion. [OR=0.73, $95 \% \mathrm{Cl}$ $(0.31,1.68), p=0.45]$.

- Rate of rash 
Two studies include eligible data on rate of rash between dexamethasone treated and dexamethasone free patients before blood transfusion, consisting of 4955 cases. A fixed model was conducted because of low heterogeneity among studies (I2=0\%). Pooled statistics showed no significant difference between dexamethasone treated and dexamethasone free group concerning rate of rash caused by blood transfusion. [OR=1.32, $95 \% \mathrm{Cl}(0.57,3.05), \mathrm{p}=0.51]$.

\section{- Rate of airway spasm}

Two studies include eligible data on rate of airway spasm between dexamethasone treated and dexamethasone free patients before blood transfusion, consisting of 4955 cases. A fixed model was conducted because of low heterogeneity among studies (I2=0\%). Pooled statistics showed no significant difference between dexamethasone treated and dexamethasone free group concerning rate of airway spasm caused by blood transfusion. $[\mathrm{OR}=0.71,95 \% \mathrm{Cl}$ $(0.19,2.67), p=0.61]$.

\section{- Rate of overall transfusion reaction}

All four included studies include eligible data on overall rate of transfusion reaction between dexamethasone treated and dexamethasone free patients before blood transfusion, consisting of 18922 cases. A fixed model was conducted because of low heterogeneity among studies (I2=0\%). Pooled statistics showed no significant difference between dexamethasone treated and dexamethasone free group concerning overall rate of transfusion reaction caused by blood transfusion. [OR=0.77, 95\% $\mathrm{Cl}(0.52,1.13), \mathrm{p}=0.18]$.

Outcomes of dexamethasone on preventing transfusion reaction are illustrated in Fig. 5.

\section{Outcomes of chlorpheniramine on transfusion reaction}

\section{- Rate of febrile non hemolytic}

Two studies include eligible data on rate of fever between chlorpheniramine treated and chlorpheniramine free patients before blood transfusion, consisting of 1447 cases. A fixed model was conducted because of low heterogeneity among studies (I2=0\%). Pooled statistics showed no significant difference between chlorpheniramine treated and chlorpheniramine free group concerning rate of fever caused by blood transfusion. [OR=0.42, 95\% $\mathrm{Cl}(0.17,1.04)$, $\mathrm{p}=0.06]$. The results were shown in Fig 6 .

\section{Discussion}

Our meta-analysis collected the most updated researches regarding patient outcomes after the administration of transfusion pre-medications before transfusion. Conversely, our study failed to reveal any positive outcome toward the use of chlorpheniramine, promethazine or dexamethasone before transfusion. We found that there is no significant difference between transfusion pre-medications treated and transfusion pre-medications free group concerning the rate of fever, itchy skin, rash, airway spasm and overall transfusion reaction rate. When the patient received blood or certain blood content (platelet, red blood cell, serum, etc.), human leukocyte antigen (HLA) from the donor is transferred into the host, causing lymphocytes activated ${ }^{[23]}$. When the host receives transfusion therapy later, antigen-antibody reaction activates, leading to release of inflammatory factors and transfusion reaction.

Prevention of transfusion reaction include the following two aspects, one is purification and the other is pretransfusion transfusion pre-medications. Purification of the blood cell before transfusion is an important process to reduce the rate of transfusion reaction, which is recommended in several reviews ${ }^{[24]}$. However, the immune system mediated transfusion reaction cannot be totally avoided merely through these physical process. Chlorpheniramine and 
promethazine are H-receptor blockers. With the ability of blocking H-receptor, attenuating histamine conducted vessel dilation and tissue edema, chlorpheniramine and promethazine are able to suppress histamine-mediated allergic reaction. Dexamethasone, as glucocorticoid, maintains the ability of attenuating lymphocytes activation and palliating inflammatory reactions. Dexamethasone is also capable of suppressing IL-1 $\beta, I L-8, C 3 a, C 4 a$ and other kinds of inflammatory factors, which may sustain the immune system during the transfusion period ${ }^{[25,26]}$. Currently, transfusion pre-medications such as chlorpheniramine, promethazine and dexamethasone are administered before blood transfusion in some medical centers. However, there are certain kinds of adverse drug effect due to the use of these transfusion pre-medications and even some patient is allergic to glucocorticoid ${ }^{[27]}$. Still, there is still lacking high quality evidence for the use of transfusion pre-medications in priority to the blood transfusion.

Seemingly, a meta-analysis published in 2013 also showed that administering transfusion pre-medications before blood transfusion cannot reduce the rate of fever, indicating that the use of these drugs before blood transfusion may not lead to clinical benefit for the patient ${ }^{[28]}$. The previous study also failed to take other kinds of transfusion premedications such as chlorpheniramine or promethazine into consideration. We took a further step to investigate all generally used transfusion pre-medications and common manifestations of transfusion, aiming to provide more qualified evidence for or against the use of transfusion pre-medications before transfusion. Nevertheless, we found that chlorpheniramine, promethazine or dexamethasone is not effective in preventing transfusion reaction regardless of the clinical severity.

Conventionally, chlorpheniramine, promethazine and dexamethasone were thought to be able to suppress inflammatory reactions. However, the main mechanism for dexamethasone on suppressing inflammatory reactions is lying under the path of reducing lymphocyte activation, while chlorpheniramine and promethazine maintain the $\mathrm{H}$ receptor blocking activity. But the types of suppressed antibody by these drugs are not completely clarified up to now. Thus, chlorpheniramine, promethazine and dexamethasone may fail to attenuate anti-platelet antibodies or HLA, which act an important role in transfusion reaction ${ }^{[29]}$.

Our meta-analysis collected the most updated evidence and found that chlorpheniramine, promethazine or dexamethasone fails to reduce the rate of overall transfusion reaction. Taking into consideration that these drugs may cause adverse effect such as nausea, stressed ulcer, infection and other adverse drug reaction, we suggest that chlorpheniramine, promethazine or dexamethasone not administered before blood transfusion if only considered as allergic prevention agents.

However, there are still some limitations before drawing a solid conclusion to remove the use of dexamethasone from blood transfusion. Firstly, we only identified eight articles and merely two of them is RCT. Risk of bias from the research procedure may also hinder us from providing high quality evidence against the use of transfusion pre-medications before blood transfusion. Secondly, the rate of underlying allergic or autoimmune disease was not illustrated. Thirdly, all current researches failed to report long-term drug adverse events such as the influence on mineral and bone metabolism, as well as the use of transfusion pre-medications in auto-immune disease patient still needs further investigations. Fourthly, the outcomes from each article failed to be classified according to the types of blood product. Fifthly, we fail to report the use of acetaminophen on preventing febrile on hemolytic reactions because there is only one related article. However, our study is the first to synthesis the outcomes of itchy skin and airway spasm after the use of transfusion pre-medications in prevention of blood transfusion.

Currently, our study is the merely research reporting integrated rate of itchy skin and airway spasm concerning the prevention function of transfusion pre-medications before transfusion. Additionally, we collected all updated data demonstrating that the use of transfusion pre-medications before transfusion cannot reduce the overall rated of transfusion reaction, suggesting that the routine administration of chlorpheniramine, promethazine or dexamethasone 
before transfusion is not effective. However, further large sample, multiple center RCTs are still needed to provide high quality evidence for or against the use of transfusion pre-medications before transfusion.

\section{Conclusion}

Chlorpheniramine, promethazine or dexamethasone before blood transfusion may not be able to reduce the rate of fever, itchy skin, rash, airway spasm and overall rate of transfusion reaction, partly due to its anti-allergic functions. However, large sample, multiple center RCTs are still need to provide high quality evidence for drawing a solid conclusion.

\section{Abbreviations}

RCT, Randomized Controlled Trial,

OR, Odds ratio,

SMD, Standardized Mean Difference,

Cl, Convinced Interval,

HLA, Human Leukocyte Antigen.

\section{Declarations}

Ethic approval and consent to participate

Not applicable.

\section{Consent for publication}

Not applicable.

\section{Availability of data and materials}

All data generated or analysed during this study are included in this published article.

\section{Declaration of Conflicting Interests}

The authors declare they have no competing interest.

\section{Funding}

Not applicable.

\section{Authors' contributions}

Shiyuan Yu, Yawei Liu and Xin Lu identified including articles and analyzed the statistics. Shiyuan Yu and Yawei Liu were major contributors in writing the manuscript. Huadong Zhu and Zengzheng Ge helped to deal with baseline characteristics. Yi Li and Yanxia Gao read and modify the manuscript. All author approve the final manuscript.

\section{Acknowledgement}


Not applicable.

\section{References}

[1]. Braeutigam KH and Kolb H, Treatment of a hemolytic blood transfusion accident. Bibl Haematol, 1964. 20: $92-$ 96.

[2]. Kalff G, Janiak B and Kalinke G, Successful resuscitation after afibrinogenemia and cardiac arrest. Geburtshilfe Frauenheilkd, 1967. 27(4): 408-413.

[3]. Delaney MD, et al, Transfusion reactions: prevention, diagnosis, and treatment. Lancet, 2016. 388(10061): 2825-2836.

[4]. Ikebe $\mathrm{E}$, et al, Reduction in adverse transfusion reactions with increased use of washed platelet concentrates in Japan-A retrospective multicenter study. Transfusion and Apheresis Science, 2019.

[5]. Vinci GG and Colonna U, dexamethasone and heterologous blood transfusion. Riv Patol Clin, 1959. 14: 860870.

[6]. Domenico A, Effects of natural and synthetic corticoids on transfusional shock in the rat. Endocrinology, 1965. 77(5): 954-958.

[7]. Lichtenfeld KM and Schiffer CA, The effect of dexamethasone on platelet function. Transfusion, 1979. 19(2): 169-172.

[8]. Hiemstra IH, et al, Dexamethasone promotes granulocyte mobilization by prolonging the half-life of granulocyte-colony-stimulating factor in healthy donors for granulocyte transfusions. Transfusion, 2017. 57(3): 674684.

[9]. Heideveld E, et al, Glucocorticoids induce differentiation of monocytes towards macrophages that share functional and phenotypical aspects with erythroblastic island macrophages. Haematologica, 2018. 103(3): $395-405$.

[10]. Maharaj D, et al, Young donor white blood cell immunotherapy induces extensive tumor necrosis in advancedstage solid tumors. Heliyon, 2017. 3(10): e00438.

[11]. Coker SA, et al, A Study of the Pharmacokinetic Properties and the In Vivo Kinetics of Erythrocytes Loaded With Dexamethasone Sodium Phosphate in Healthy Volunteers. Transfus Med Rev, 2018. 32(2): 102-110.

[12] Ocon AJ, et al, Safe usage of anakinra and dexamethasone to treat refractory hemophagocytic lymphohistiocytosis secondary to acute disseminated histoplasmosis in a patient with HIV/AIDS. BMJ Case Rep, 2017.

[13]. Frazier SK, et al, Adverse Reactions to Transfusion of Blood Products and Best Practices for Prevention. Crit Care Nurs Clin North Am. 2017 Sep;29(3):271-290.

[14]. Rujkijyanont P, et al, Efficacy of Oral Acetaminophen and Intravenous Chlorpheniramine Maleate versus Placebo to Prevent Red Cell Transfusion Reactions in Children and Adolescent with Thalassemia: A Prospective, Randomized, Double-Blind Controlled Trial. Anemia, 2018. 2018: 1-8.

[15]. Lei Xue, Analysis of the effect of preventive medication before transfusion on allergic reaction to blood transfusion. China practical medicine, 2014(19): 174-175. 
[16]. Li Cai, The role of pre-transfusion administration in preventing adverse reactions of transfusion. Chinese and foreign women's health research, 2016(23): 27-28.

[17]. Lijuan Liu, et al. Effect of preventive medication before transfusion on adverse reactions of transfusion. Clinical transfusion and analysis. 2017, 19(6): 559-560.

[18]. Hua Zhang, et al, Observation on Efficacy of Dexamethasone in Preventing Adverse Blood Transfusion reactions. Evaluation and analysis of drug-use in hospitals of China, 2017(09): 1206-1207+1210.

[19]. Minhong Hu, Clinical observation of chlorpheniramine injection in preventing transfusion reaction. Strait Pharmacy. 2013, 25(2): 268-269.

[20]. Limin Hu, et al, Atminstration of medicine before blood transfusion to prevent blood transfusion adverse reactions. Journal of tropical medicine, 2014(11): 1445-1448.

[21].Hucheng Luo, et al, 囚etrospective Investigation into the Prevention of Adverse 『eactions by Medicine Before Blood Transfusion. Medical \ecapitulate, 2015(07): 1328-1330.

[22]. Hui Dai, Clinical observation of chlorpheniramine in preventing transfusion reaction. Zhejiang Medicine Journal, 2016(21): 1769-1770.

[23]. Zhang T, et al, Successful treatment with intrauterine delivery of dexamethasone for repeated implantation failure. Am J Reprod Immunol, 2017. 78(6).

[24]. Osterman JL and Arora S, Blood Product Transfusions and Reactions. Hematology/Oncology Clinics of North America, 2017. 31(6): 1159-1170.

[25]. Thomas $L$, et al, Selective upregulation of TNFalpha expression in classically-activated human monocytederived macrophages (M1) through pharmacological interference with V-ATPase. Biochem Pharmacol, 2017. 130: 7182.

[26]. Strauss RG, Neutrophil/granulocyte transfusions collected from G-CSF + dexamethasone-stimulated donors. Curr Opin Hematol, 2015. 22(6): 565-567.

[27]. van Osch D, et al, Intraoperative High-Dose Dexamethasone in Cardiac Surgery and the Risk of Rethoracotomy. Ann Thorac Surg, 2015. 100(6): 2237-2242.

[28]. Jianshe Cui, et al. Meta analysis of two drugs to prevent fever and allergic transfusion reaction. Laboratory medicine, 2013, 10(10):1307-1309.

[29]. Heuft HG, Goudeva L and Blasczyk R, A comparative study of adverse reactions occurring after administration of glycosylated granulocyte colony stimulating factor and/or dexamethasone for mobilization of neutrophils in healthy donors. Ann Hematol, 2004. 83(5): 279-285.

\section{Tables}

Table1. Included articles 


\begin{tabular}{|c|c|c|c|c|c|c|c|}
\hline Research & Journal & $\begin{array}{l}\text { Journal } \\
\text { (in } \\
\text { Chinese) }\end{array}$ & Type* & $\mathbf{N}$ & Treatment & Control & $\begin{array}{l}\text { Type of } \\
\text { transfusion }\end{array}$ \\
\hline $\begin{array}{l}\text { Minhong } \\
\text { Hu } 2013\end{array}$ & \multirow{2}{*}{$\begin{array}{l}\text { Strait } \\
\text { Pharmaceutical } \\
\text { Journal } \\
\text { Zhejiang } \\
\text { Medical } \\
\text { Journal }\end{array}$} & वस्ता & RCT & 292 & $\begin{array}{l}\text { Chlorpheniramine } \\
10 \mathrm{mg} \text { im }\end{array}$ & \multirow{2}{*}{$\begin{array}{l}\text { Calcium } \\
\text { gluconate } \\
10 \mathrm{ml} \text { iv } \\
\text { No drug } \\
\text { administered }\end{array}$} & $\begin{array}{l}\text { Not } \\
\text { clarified }\end{array}$ \\
\hline $\begin{array}{l}\text { Hui Dai } \\
2016\end{array}$ & & 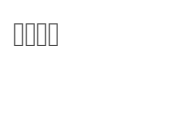 & CS & 2155 & $\begin{array}{l}\text { Chlorpheniramine } \\
4 \mathrm{mg} \text { po }\end{array}$ & & $\begin{array}{l}\text { Not } \\
\text { clarified }\end{array}$ \\
\hline$\underset{2014}{\operatorname{Limin}} \mathrm{Hu}$ & $\begin{array}{l}\text { Journal of } \\
\text { tropical } \\
\text { medicine }\end{array}$ & 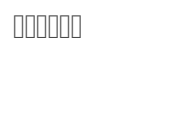 & CS & 362 & \multirow{2}{*}{$\begin{array}{l}\text { Promethazine } \\
25 \mathrm{mg} \text { or } \\
\text { dexamethasone } \\
5 \mathrm{mg} \text { im } \\
\text { Promethazine } \\
25 \mathrm{mg} \text { or } \\
\text { dexamethasone } \\
6 \mathrm{mg} \text { im }\end{array}$} & $\begin{array}{l}\text { No drug } \\
\text { administered }\end{array}$ & $\begin{array}{l}\text { Erythrocyte, } \\
\text { serum and } \\
\text { platelet }\end{array}$ \\
\hline $\begin{array}{l}\text { Hucheng } \\
\text { Luo } \\
2015\end{array}$ & $\begin{array}{l}\text { Medical } \\
\text { Recapitulate }\end{array}$ & טבטם & CS & 329 & & $\begin{array}{l}\text { No drug } \\
\text { administered }\end{array}$ & $\begin{array}{l}\text { Not } \\
\text { clarified }\end{array}$ \\
\hline \multirow{3}{*}{$\begin{array}{l}\text { Lei Xue } \\
2014 \\
\text { Li Cai } \\
2016 \\
\text { LiJuan } \\
\text { Liu } 2017\end{array}$} & \multirow{4}{*}{$\begin{array}{l}\text { China Practical } \\
\text { Medicine } \\
\text { Sichuan } \\
\text { Medicine } \\
\text { Clinical } \\
\text { Transfusion } \\
\text { and Testing } \\
\text { Evaluation and } \\
\text { Analysis of } \\
\text { Drug-use in } \\
\text { Hospital of } \\
\text { China } \\
\end{array}$} & 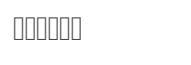 & CS & 4745 & \multirow{3}{*}{$\begin{array}{l}\text { Dexamethasone, } \\
\text { dose not reported } \\
\text { Dexamethasone } \\
5 \mathrm{mg} \text { iv } \\
\text { Dexamethasone } \\
5 \mathrm{mg} \text { iv }\end{array}$} & No drug & \multirow{4}{*}{$\begin{array}{l}\text { Not } \\
\text { clarified } \\
\text { Not } \\
\text { clarified } \\
\text { Erythrocyte, } \\
\text { serum and } \\
\text { platelet } \\
\text { Not } \\
\text { clarified }\end{array}$} \\
\hline & & מבסם & CS & 210 & & NS $5 \mathrm{ml}$ iv & \\
\hline & & 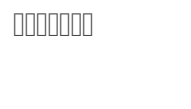 & CS & 13642 & & $\begin{array}{l}\text { No drug } \\
\text { administered }\end{array}$ & \\
\hline $\begin{array}{l}\text { Hua } \\
\text { Zhang } \\
2018\end{array}$ & & | & RCT & 325 & $\begin{array}{l}\text { Dexamethasone } \\
5-10 \mathrm{mg} \text { iv }\end{array}$ & $\begin{array}{l}\text { No drug } \\
\text { administered }\end{array}$ & \\
\hline
\end{tabular}

*CS: Case control study

RCT: Randomized controlled study

Table1. Baseline characteristics

\begin{tabular}{|c|c|c|c|}
\hline & Dexamethasone & Control & $\bar{P}$ \\
\hline & $\begin{array}{lr}\text { Mean } & \text { SD } \\
\end{array}$ & Mean SD & \\
\hline $\begin{array}{l}\text { Cases }\left(N^{*} \text { transfusion cases }\right) \\
\text { Male (N)* } \\
\text { Age (y) }\end{array}$ & $\begin{array}{lr} & 9222 \\
229 & 17.8 \\
40.4 & 5.4\end{array}$ & 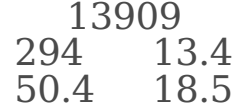 & $\begin{array}{l}0.911 \\
0.593\end{array}$ \\
\hline
\end{tabular}

*Some articles missed the number of gender in each group

Table3. Main outcomes 


\begin{tabular}{|c|c|c|c|}
\hline \multirow{2}{*}{ Overall effect } & OR & 95\%CI & $P$ \\
\hline & & & \\
\hline Rate of fever & 0.70 & {$[0.46,1.06]$} & 0.10 \\
\hline Rate of itchy & 0.73 & {$[0.31,1.68]$} & 0.45 \\
\hline Rate of rash & 1.19 & {$[0.55,2.58]$} & 0.67 \\
\hline Rate of overall transfusion reaction & 0.82 & {$[0.62,1.09]$} & 0.16 \\
\hline Effect of dexamethasone & & & \\
\hline Rate of fever & 0.67 & {$[0.29$} & 0.33 \\
\hline Rate of itchy & 0.73 & {$[0.31,1.68]$} & 0.45 \\
\hline Rate of rash & 1.32 & {$[0.57,3.05]$} & 0.51 \\
\hline Rate of airway spasm & 0.71 & {$[0.19,2.67]$} & 0.61 \\
\hline Rate of overall transfusion reaction & 0.77 & {$[0.52,1.13]$} & 0.18 \\
\hline Effect of chlorpheniramin & & & \\
\hline Rate of fever & 0.42 & {$[0.17,1.04]$} & 0.06 \\
\hline
\end{tabular}

\section{Figures}

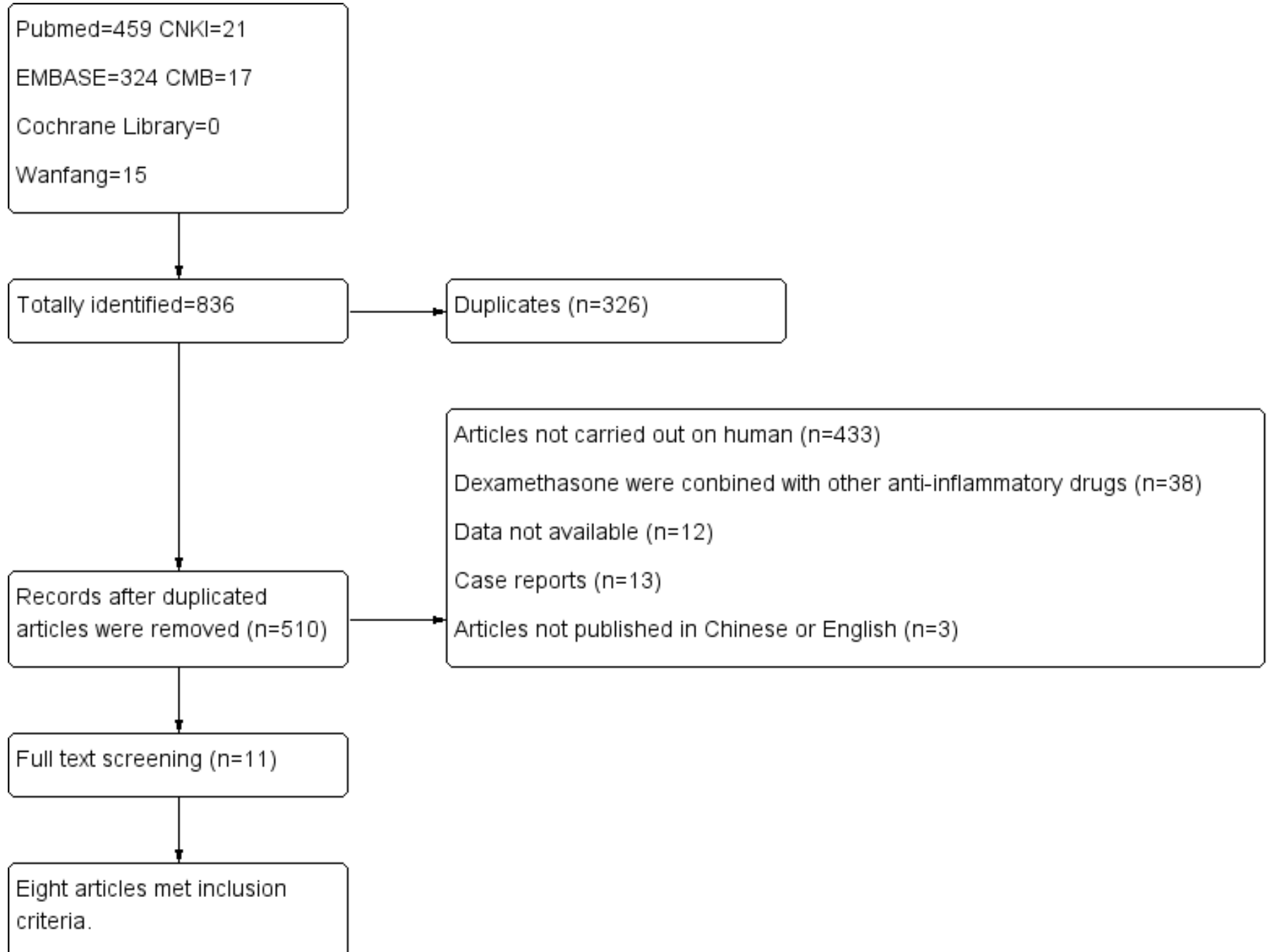

Figure 1

Flow diagram of study enrollment 
Random sequence generation (selection bias)

Allocation concealment (selection bias)

Blinding of participants and personnel (performance bias)

Blinding of outcome assessment (detection bias)

Incomplete outcome data (attrition bias)

Selective reporting (reporting bias)

Other bias
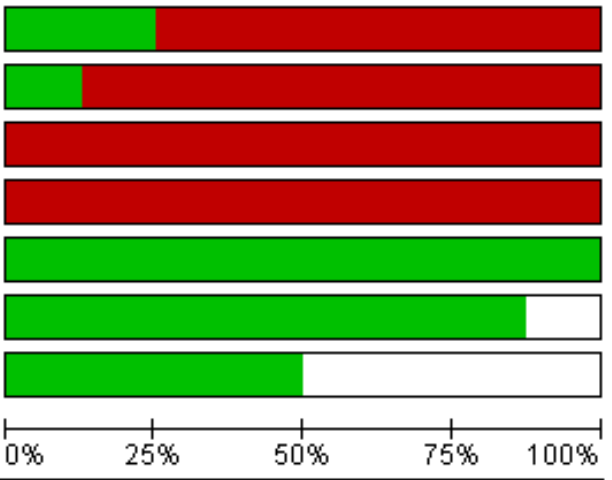

Low risk of bias

Unclear risk of bias

High risk of bias

Figure 2

Risk of bias

\begin{tabular}{|c|c|c|c|c|c|c|c|}
\hline & 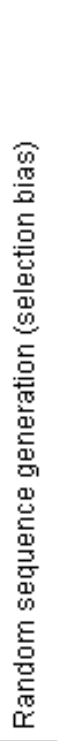 & 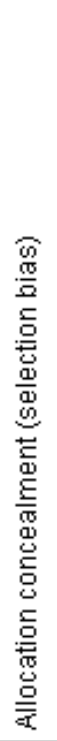 & 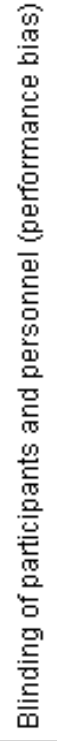 & 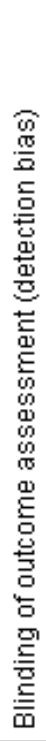 & 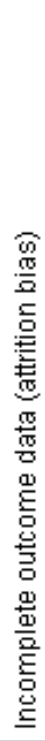 & 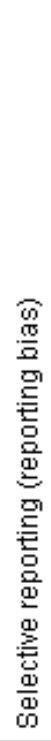 & 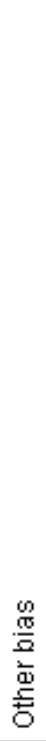 \\
\hline \multicolumn{8}{|l|}{ Hua Zhang 2018} \\
\hline \multicolumn{8}{|l|}{ Hucheng Luo 2015} \\
\hline \multicolumn{8}{|l|}{ Hui Dai 2016} \\
\hline \multicolumn{8}{|l|}{ Lei Xue 2014} \\
\hline \multicolumn{8}{|l|}{ Li Cai 2016} \\
\hline \multicolumn{8}{|l|}{ Lijuan Liu 2017} \\
\hline \multicolumn{8}{|l|}{ Limin Hu 2014} \\
\hline Minhong Hu 2013 & + & + & & & + & + & + \\
\hline
\end{tabular}

Figure 3

Risk of bias summary 


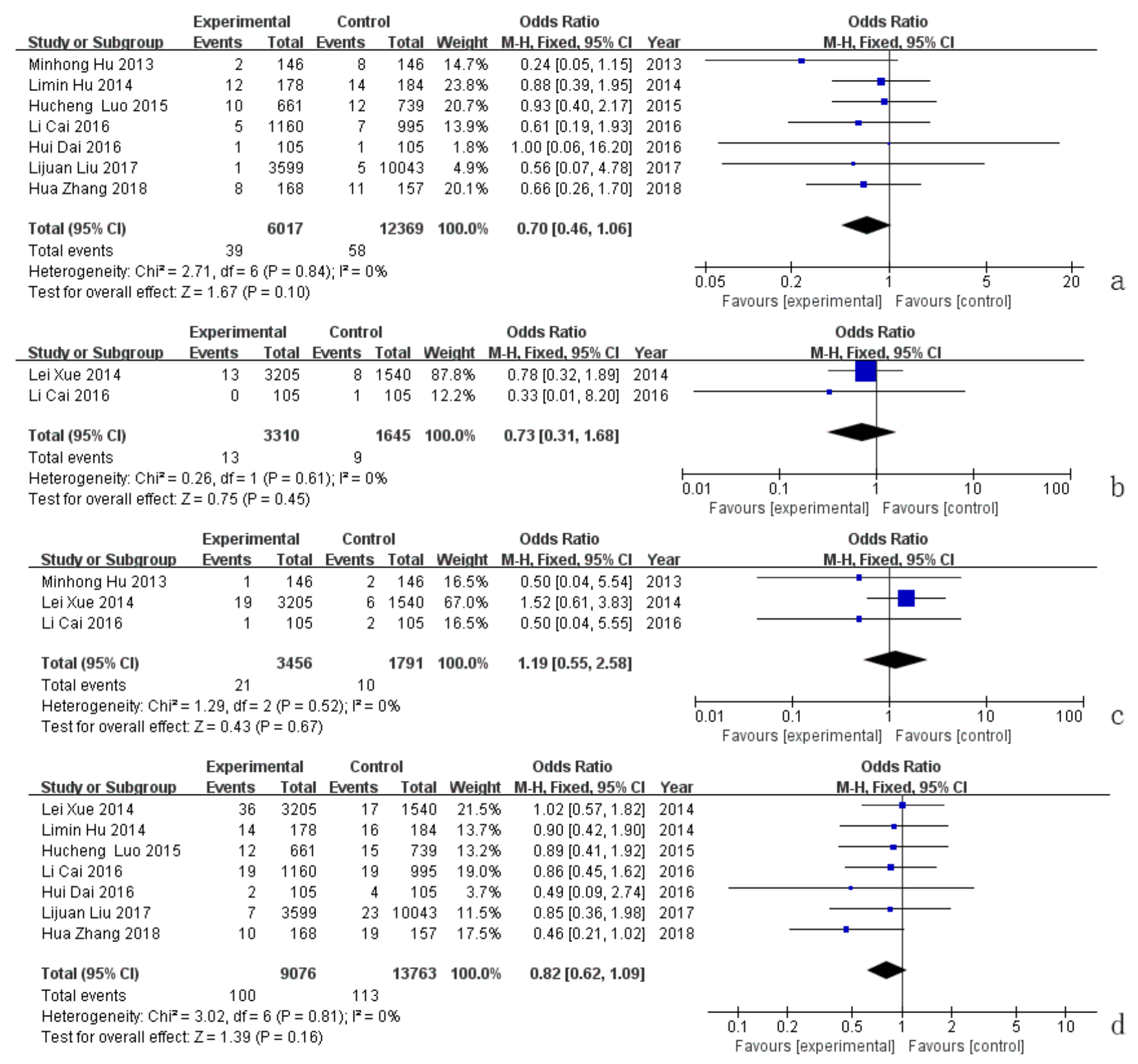

\section{Figure 4}

Overall effect of transfusion pre-medications on transfusion reaction, a) rate of fever, b) rate of itchy skin, c) rate of rash, d) rate of overall transfusion reaction. 


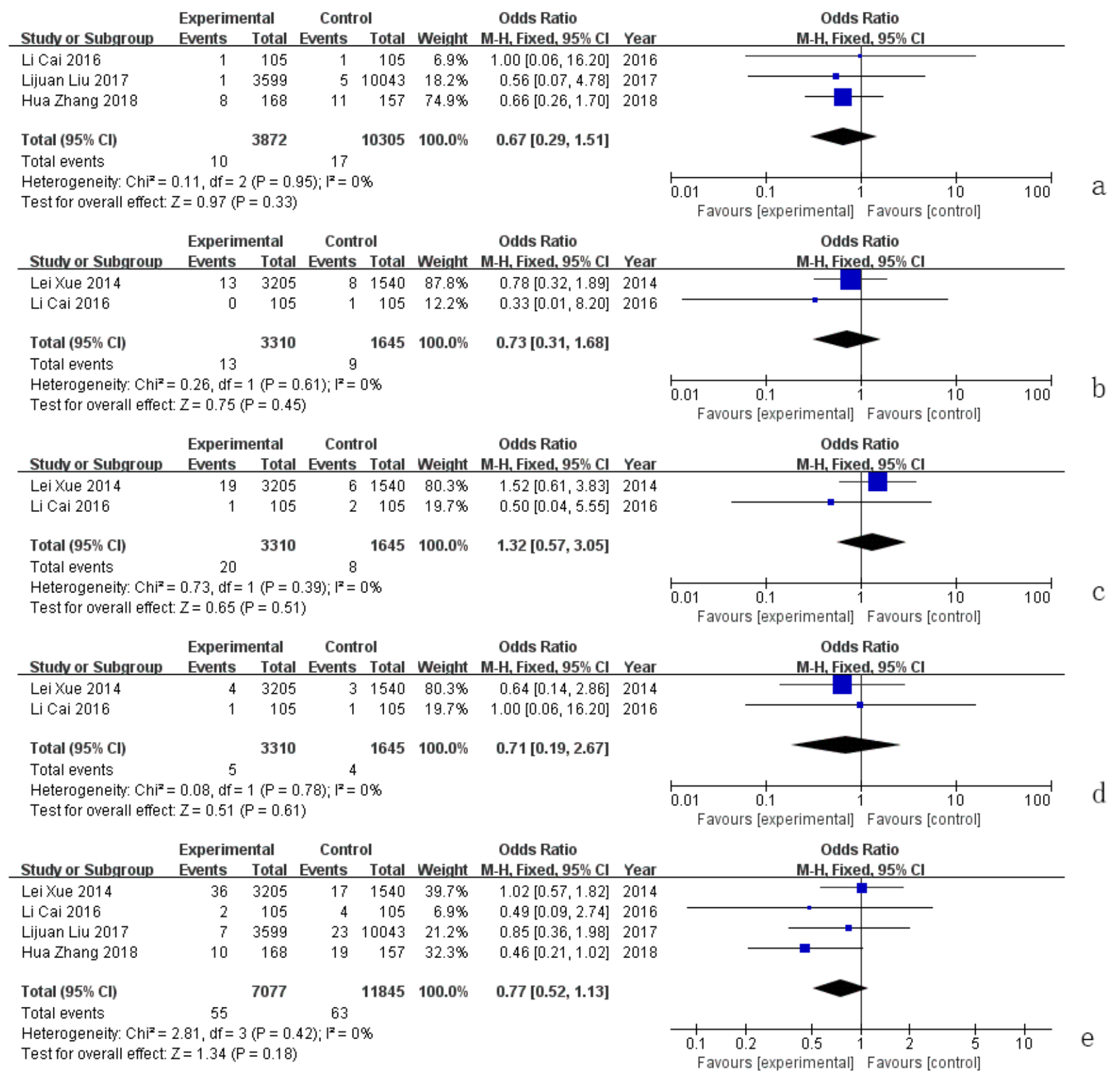

\section{Figure 5}

Outcomes of dexamethasone on preventing transfusion reaction, a) rate of fever, b) rate of itchy skin, c) rate of rash, d) rate of airway spasm, e) rate of overall transfusion reaction.

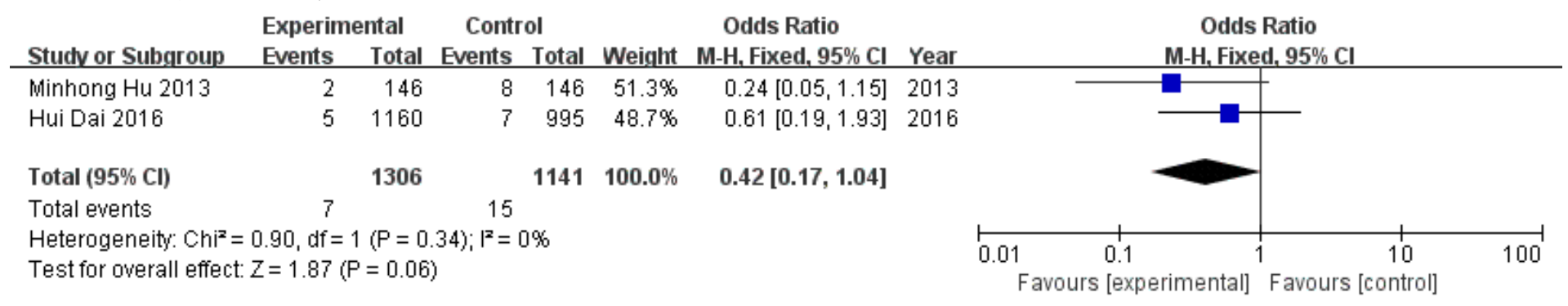

\section{Figure 6}


Effect of chlorpheniramine on preventing fever during transfusion

\section{Supplementary Files}

This is a list of supplementary files associated with this preprint. Click to download.

- PRISMA2009Checklist.doc 